Table 1

Mean Semantic Differential Changes

\begin{tabular}{|c|c|c|c|c|c|c|c|c|c|c|c|c|}
\hline \multirow{3}{*}{$\begin{array}{l}\text { Word } \\
\text { Group }\end{array}$} & \multicolumn{4}{|c|}{ Evaluation } & \multicolumn{4}{|c|}{ Potency } & \multicolumn{4}{|c|}{ Activity } \\
\hline & \multicolumn{2}{|c|}{ PDS } & \multicolumn{2}{|c|}{ MDS } & \multicolumn{2}{|c|}{ PDS } & \multicolumn{2}{|c|}{ IIDS } & \multicolumn{2}{|c|}{ PDS } & \multicolumn{2}{|c|}{ MDS } \\
\hline & Error & No Error & Error & No Error & Error & No Error & Error & No Error & Error & No Error & Error & No Error \\
\hline CA & 20.10 & 6.70 & -33.30 & 13.40 & 20.00 & 16.60 & 9.90 & -6.60 & 3.40 & 3.40 & 130.00 & 29.90 \\
\hline SSA & 20.00 & 59.90 & 26.70 & -6.70 & 10.00 & 40.10 & -10.00 & 13.40 & 13.30 & 39.80 & -6.70 & 9.90 \\
\hline NA & 20.10 & -16.60 & -30.00 & 16.60 & 0.00 & 26.60 & 6.60 & 0.10 & 43.30 & 20.00 & -29.80 & 13.30 \\
\hline
\end{tabular}

method effect $\left(\mathrm{q}^{\prime}=-6.31, \mathrm{p}<.01\right)$ and a significant error effect $\left(\mathrm{q}^{\prime}=4.50, \mathrm{p}<.05\right)$ confirm this finding. Of the interactions one Group by Method significant effect occurred. This was between CA and NA on $\operatorname{MDS}\left(\mathrm{q}^{\prime}=4.29, \mathrm{p}<.05\right)$.

Table 1 presents the means for the semantic differential changes. It may be seen that mean patterns for the evaluative and activity factors differ from each other as expected and in confirmation of the paired comparisons previously described. DISCUSSION

The present study supports Kasschau's finding that connotative changes following semantic satiation occur primarily on the activity factor, even when paired associates rather than single words are employed. Loss of meaning does not occur, however, for either member of the word pair alone. Semantic satiation is associated with meaning loss only when both members of the word pair are affected, i.e., $\mathrm{A}$ is not recalled. This finding is consistent with the interpretation that meaning reflects association between words rather than something that affects either member of a word pair alone.

The finding of Kannango \& Lambert (1963) that paired-associate learning is impaired when either of the associates is subjected to previous semantic satiation raises the question: Must initial meaning intensity be high for satiation effects to be found after the paired association is learned? In this study word group, effects occurred only on the activity factor and only when MDS was used, indicating that meaning intensity does not figure greatly in the present results. Kasschau (1969) also found for single words that high initial meaning was related to meaning loss only using the MDS measure. These results for both single words and paired associates question the propriety of the bipolarity assumption. Comparison of satiation effects for unipolar and bipolar scales should aid in the formulation of this problem.

\section{REFERENCES}

GOLDMAN, J., COSTANZO, P. R., \& LEHRKE, S. H. Semantic satiation as a function of type of associate. Psychonomic Science, 1968, 12 . 267-268.
KANNANGO, R. N., \& LAMBERT, W. E. Paired associate learning as a function of stimulus and response satiation. British Journal of Psychology, 1963, 54, 135-144.

KASSCHAL, R. A. Semantic satiation as a function of duration of repetition and initial meaning intensity. Journal of Verbal Learning \& Verbal Behavior, 1969, 8, 36-42.

KIRK, R. E. Experimental design procedures for the behavioral sciences. Belmont, Calif: Roger E. Kirk, Brooks/Cole, 1968.

LAMBERT, W. E., \& JAKOBOVITS, L. A
Verbal satiation and changes in the intensity of meaning. Journal of Experimental Psychology, 1960, 60, 376-383.

LEAGUE, R. Satiation in semantic space. In $T$. A. Sebeok (Ed.), Semiotica. The Hague: Mouton, 1970.

OSGOOD, C. E., SUCI, G. J., \& TANNENBAUM $\mathrm{P}$. H. The measurement of meaning. Lirbana, Ill: University of Illinois Press, 1957.

YELEN, D. R., \& SCHULZ, R. W. Verbal satiation. Journal of Verbal Learning \& Verbal Behavior, 1963, 1, 372-377.

\title{
Proactive inhibition of initial items in short-term recall*
}

\author{
THOMAS W. TURNAGE \\ University of Maryland, College Park, Md. 20742
}

Short-term recall of serial lists as a function of item frequency and prior testing was investigated. The experimental results suggested that (1) interference from prior testing obtained for initial items in the list but not terminal items, and (2) frequency had no effect on recall because the experimental method equated item availability across that dimension.

Repetition of inputs has long been regarded as a critical determinant of long-term memory; yet, there is evidence to suggest that a single input of digit strings may result in long-term store at least for some of the items (Hebb, 1961; Melton, 1963). Bartz (1969) has argued that such stable storage involves only the "first-presented" (initial) items in the string, while the "last-presented"

*This research was supported by a grant to the Center for Language and Cognition from the Biomedical Science Support Committee of the University of Maryland. Computer time for this project was supported by National Aeronautics and Space Administration Grant NsG-398 to the Computer Science Center at the University of Maryland. (terminal) items are carried in short-term store.

The present study represents a further investigation of the effects of single inputs on short-term and long-term store. However, in place of digits, verbal items varying in frequency of occurrence in the written language were used as experimental units, and the major focus was on cumulative effects of proactive inhibition (PI) deriving from repeated testing. It was anticipated that PI effects, which necessarily involve retention of prior inputs, would be greater for initial items in a serial list to the extent that these items are more likely to enter long-term store following a single input than are terminal items. 
Table 1

Mean Serial Recall as a Function of Serial Position and Blocks

\begin{tabular}{lcccccccccccc}
\hline & \multicolumn{10}{c}{ Serial Position } & & Row \\
Blocks & 1 & 2 & 3 & 4 & 5 & 6 & 7 & 8 & 9 & 10 & Means \\
\hline I & 2.46 & 1.52 & 1.20 & 0.88 & 0.74 & 0.67 & 0.53 & 0.56 & 0.82 & 1.74 & 1.11 \\
II & 2.17 & 1.35 & 0.89 & 0.76 & 0.70 & 0.58 & 0.51 & 0.78 & 0.86 & 1.82 & 1.04 \\
III & 2.10 & 1.52 & 1.20 & 0.76 & 0.70 & 0.54 & 0.57 & 0.75 & 1.08 & 1.86 & 1.11 \\
Mean & 2.24 & 1.46 & 1.10 & 0.80 & 0.71 & 0.60 & 0.54 & 0.70 & 0.92 & 1.80 & \\
\hline
\end{tabular}

\section{EXPERIMENTAL MATERIALS}

The basic experimental materials were lists of 10 items of two syllables, with the lists varying in frequency across three levels. These lists were formed by using 24 each of high-frequency (HF), medium-frequency (MF), and low-frequency (LF) items from sources described by Turnage \& McCullough (1968). The HF and MF items were nouns whose average printed frequency ("L"-count; Thorndike \& Lorge, 1944) was 50 and 10 , respectively. The LF items were paralogs with an average printed frequency of 0 . Within frequency levels, items were almost zero in interitem associative strength, according to norms.

At a given frequency level, five items were assigned at random to four subsets: A, B, C, and D. Then, four serial lists of 10 items each were generated by combining items from Subsets A and B for the first list, $C$ and D for the second list, $A$ and D for the third list, and $B$ and $C$ for the fourth list. This gave 12 different serial lists, with four at each frequency level. Next, nine serial orders were assigned to each serial list by random numbers. Finally, each list of items was typed in alphabetical order on the page of a booklet in which $S$ was to write. This method insured that the pool of verbal items would be available and that failures of recall would, primarily, reflect the forgetting of order as in the case of digit span.

\section{PROCEDURE}

The Ss were tested in groups of six, as they entered the laboratory, on the basis of an unsystematic testing order for the 12 experimental conditions: viz, 3 levels of frequency by 4 serial lists.

The list items were presented singly on a rear-projection screen at a $1-\mathrm{sec}$ rate. When the last item was presented, the Ss turned to a page of the booklet before them where the items just shown were typed in alphabetical order. The $\mathrm{Ss}$ then indicated the order in which the items had appeared by placing the numbers 1.10 after the appropriate items. (A simple example, involving nonexperimental words had been given to each $\mathrm{S}$ at the beginning of the experiment to insure his understanding of the task.) The Ss were given $30 \mathrm{sec}$ for the recall task. Following this, the next serial ordering of the experimental items was presented, and the $\mathrm{Ss}$ repeated the recall task. This procedure was continued until the $S s$ had been given nine study-recall trials, with the serial order of the experimental items changing on each trial. SUBJECTS

A total of 72 Ss who were meeting the requirements of an introductory course in psychology were used in this experiment. All Ss had English as their native language or had spoken it for the previous 5 years. RESULTS

The basic measure of serial recall was the number of items numbered correctly with respect to serial position. For convenience of analysis, serial recall scores for Study-Test Trials 1-3, 4-6, and $7-9$ were grouped together into Blocks 1, 2, and 3, respectively. Table 1 shows mean recall as a function of blocks and serial position.

\section{Serial Position Effects}

An analysis of variance for the data in Table 1 indicated that only the main effect of serial position, $F(9,621)=88.04$, $p<.01$, and the Serial Position by Blocks interaction, $F(18,1252)=1.68, p<.05$, were reliable sources of variance. As Table 1 shows, the serial position effect was due to the usual primacy-recency effect found in serial leaming. The form of the Serial Position by Blocks interaction suggested that recall of initial items was being depressed with repeated testing. In order to evaluate this further, Duncan's range test was applied to the three means at each of the 10 serial positions. (The mean square used to evaluate the interaction effect served in estimating the standard error of the mean used for these range tests). The range analysis indicated that (1) at the first serial position, the means for Blocks 2 and 3 did not differ reliably from each other, but they both were significantly lower than the mean for Block 1; (2) at the third serial position, the means for Blocks 1 and 3 did not differ reliably from each other, but they were both significantly higher than the mean for Block 2; and (3) there were no other reliable differences among means for the remaining serial positions at the .05 level of confidence.

\section{DISCUSSION}

The form of the Serial Position by Blocks interaction and the outcomes of the various range tests for this interaction indicate that PI effects generated by repeated testing depressed recall for initial items, but not for terminal items. This finding seems consistent with Bartz's (1969) assumption that, given a single input, "first-presented" items in a string are likely to be placed in long-term store, while "last-presented" jtems are likely to be held in short-term store. That is, if initial items in a string are favored with respect to entrance into long-term store, they are also more likely to be available to interfere with recall of initial items in subsequent strings than are terminal items. However, there may be a number of reasons why initial items are so favored, including the opportunity for differential rehearsal strategies by $S s$ in such recall situations (cf. Postman, Turnage, \& Silverstein, 1964). Thus, it is not clear that a two-factor theory of memory is necessary to explain the present data, even though they may be consistent with it.

The fact that frequency was not a significant main effect and did not enter into any reliable interactions-even though the frequency range used was wide enough to produce differences in recall following a single input (cf. Postman et al, 1964)-is probably due to the fact that the present experimental method effectively controlled differences in item availability as a function of frequency. This, in turn, indicates that the curvilinear relationship between frequency and short-term recall predicted by interference theory and found empiricially (Turnage \& McCullough, 1968) may depend greatly on superior item availability for HF lists in the "typical" serial recall situation. If this is the case, unit-sequence interference effects in short-term memory may be more a matter of failures to discriminate accurately among a "multitude" of available HF items with respect to their serial positions than a matter of associative interference as such.

\section{REFERENCES}

BARTZ, W. H. Repetition and the memory stores. Journal of Experimental Psychology, $1969,80,33-38$.

HEBB, D. O. Distinctive features of learning in the higher animal. In J. B. Delafresnaye (Ed.) Brain mechanisms and learning. New York: Oxford University Press, 1961. Pp. 37-46.

MELTON, A. W. Implications of short-term memory for a general theory of memory. Journal of Verbal Learning \& Verbal Behavior $1963,2,1-21$

POSTMAN, L., TURNAGE, T. W., \& SILVERSTEIN, A. The running memory span for words. Quarterly Joumal of Experimental Psychology, 1964, 16, 81-89.

IHORNDIKE, E. L., \& LORGE, I. The teacher's wordbook of 30,000 words. New York Bureau of Publications, Teachers College, Colkmbia University, 1944

TLRNAGE. T. W., \& McCUlloUGH, T. A. Letter-sequence and unit-sequence effects during learning and retention. Journal of Fxperimental Psychology, 1968, 76, 141-146 